\title{
Factors associated with early response to olanzapine and clinical and functional outcomes of early responders treated for schizophrenia in the People's Republic of China
}

\author{
This article was published in the following Dove Press journal: \\ Neuropsychiatric Disease and Treatment \\ 16 May 2014 \\ Number of times this article has been viewed
}

\author{
Wenyu Ye \\ William Montgomery ${ }^{2}$ \\ Zbigniew Kadziola ${ }^{3}$ \\ $\mathrm{Li} \mathrm{Liu}^{4}$ \\ Haibo Xue ${ }^{4}$ \\ Michael D Stensland ${ }^{5}$ \\ Tamas Treuer ${ }^{6}$ \\ 'Real World Analytics, Eli Lilly and \\ Company, Indianapolis, IN, USA; \\ ${ }^{2}$ Global Patient Outcomes and Real \\ World Evidence, Eli Lilly Australia \\ Pty Ltd, West Ryde, Australia; ${ }^{3}$ Real \\ World Analytics Capabilities, Eli Lilly \\ GmbH,Vienna, Austria; ${ }^{4}$ Lilly Suzhou \\ Pharmaceutical Co, Ltd, Shanghai \\ Branch, People's Republic of China; \\ ${ }^{5}$ Agile Outcomes Research, Inc., \\ Rochester, MN, USA; ${ }^{6}$ Neuroscience \\ Research, Eli Lilly and Company, \\ Budapest, Hungary
}

Background: The aims of this analysis were to identify factors associated with early response (at 4 weeks) to olanzapine treatment and to assess whether early response is associated with better longer-term outcomes for patients with schizophrenia in the People's Republic of China.

Methods: A post hoc analysis of a multi-country, 6-month, prospective, observational study of outpatients with schizophrenia or bipolar mania who initiated or switched to treatment with oral olanzapine was conducted using data from the Chinese schizophrenia subgroup $(n=330)$. Factors associated with early response were identified using a stepwise logistic regression with baseline clinical characteristics, baseline participation in a weight control program, and adherence with antipsychotics during the first 4 weeks of treatment. Mixed models for repeated measures with baseline covariates were used to compare outcomes over time between early responders and early nonresponders to olanzapine.

Results: One hundred and thirty patients (40\%) achieved an early response. Early response was independently predicted by higher baseline Clinical Global Impressions-Severity score (odds ratio [OR] 1.51, 95\% confidence interval [CI] 1.15-1.97), fewer years since first diagnosis (OR 0.94, CI 0.90-0.98), a greater number of social activities (OR 1.22, CI 1.05-1.40), participation in a weight control program (OR 1.81, CI 1.04-3.15), and high adherence with antipsychotics during the first 4 weeks of treatment (OR 2.98, CI 1.59-5.58). Relative to early nonresponders, early responders were significantly more likely to meet treatment response criteria at endpoint, had significantly greater symptom improvement (Clinical Global Impressions-Severity), and had significantly greater improvement in functional outcomes (all $P<0.05$ ).

Conclusion: High levels of adherence to prescribed antipsychotics and participation in a weight control program were associated with early response to olanzapine in Chinese patients with schizophrenia. Early response was associated with greater improvement in symptomatic, functional, and quality of life outcomes at 6 months compared with early nonresponse. Current findings are consistent with previous research outside of the People's Republic of China.

Keywords: treatment outcomes, weight reduction programs, antipsychotic agents, observational study

\section{Introduction}

Schizophrenia is a chronic and debilitating mental illness that has been ranked among the top ten causes of years lost to disability. ${ }^{1,2}$ Due to the significant degree of cognitive impairment that can accompany schizophrenia, many patients are not aware of their illness $^{3}$ and most are not able to gain employment or maintain a marriage/partner relationship. ${ }^{4,5}$ Reducing the long-term burden of schizophrenia could meaningfully

\author{
Correspondence: William Montgomery \\ Eli Lilly Australia Pty Ltd, \\ II 2 Wharf Rd, West Ryde \\ NSW 2I I4, Australia \\ Tel +6I 293254335 \\ Fax +6I 293254334 \\ Email montgomery_bill@lilly.com
}

submit your manuscript | www.dovepress.com

Dovepress

http://dx.doi.org// 0.2/47/NDT.S59468
Neuropsychiatric Disease and Treatment 2014:10 869-878

(c) (i) () 2014 Ye et al. This work is published by Dove Medical Press Limited, and licensed under Creative Commons Attribution - Non Commercial (unported, v3.0) License. The BY NC full terms of the License are available at http:///creativecommons.org/licenses/by-nc/3.0/. Non-commercial uses of the work are permitted without any further permissio request permission may be found at: http://www.dovepress.com/permissions.php 
impact individuals who are afflicted, as well as society as a whole.

The goals of treatment in schizophrenia depend on the current phase of the illness, ie, acute, stabilization, or stable. ${ }^{1,6,7}$ During an acute episode, the primary focus is on stabilizing the patient. ${ }^{1}$ In the stabilization and stable phases, the goals turn to preventing further relapses and maximizing functioning. Regardless of the phase of the illness, antipsychotic medications play a core role in treatment. Following an acute relapse, continued antipsychotic medication is recommended for a minimum of 2-5 years, and potentially throughout a patient's lifetime, because it is one of the most effective methods for preventing relapses. ${ }^{6}$ Effective short-term acute treatment (0-12 weeks) and longer-term stabilization (6-12 months) are prerequisites for reducing the long-term ( $>5$ years) burden of schizophrenia.

Antipsychotics appear to be a heterogeneous group of medications differing in efficacy and tolerability. The second-generation antipsychotics are generally preferred for first-line treatment over first-generation antipsychotics because of the reduced risk of extrapyramidal symptoms and tardive dyskinesia. ${ }^{1}$ Meta-analyses and large publicly funded clinical trials have found that the second-generation antipsychotics vary in efficacy and tolerability. ${ }^{8-10}$ Among the second-generation antipsychotics, some studies have shown olanzapine to be more effective but there may be a greater risk of weight gain and metabolic adverse events in some patients. ${ }^{8-11}$ Despite the greater risk of weight gain and metabolic adverse events for clozapine and olanzapine, there appears to be a significantly lower risk of overall mortality among patients treated with these agents. ${ }^{12}$

Adherence and persistence with antipsychotic medication regimens is often poor and can lead to treatment nonresponse in schizophrenia. ${ }^{1,7}$ In Tianjin, People's Republic of China, a recent administrative claims analysis found that less than $10 \%$ of patients with schizophrenia continued with a new antipsychotic for a full year. ${ }^{13}$ A large Asia-Pacific survey of psychiatrists reported that $54 \%$ of Chinese patients were partially or fully nonadherent with antipsychotic medication. ${ }^{14}$ Poor treatment adherence is one of the strongest predictors of relapse and hospitalization. ${ }^{15-18}$ It has been linked to lack of insight into illness, ${ }^{3,19}$ use of first-generation antipsychotics instead of second-generation antipsychotics, ${ }^{20}$ poor therapeutic alliance, ${ }^{19,21}$ comorbid substance use, ${ }^{19,21,22}$ poor treatment efficacy, ${ }^{23}$ and treatment tolerability issues. ${ }^{23}$ Understanding and improving early treatment adherence may improve longer-term outcomes.
The course and pattern of schizophrenia varies considerably from patient to patient. ${ }^{1}$ Recent work examining acute response trajectories in schizophrenia for different antipsychotics has identified multiple response patterns, including three consistent patterns, ie, patients who have a more rapid initial response, patients who have a somewhat slower response, and patients who have a poor overall response. ${ }^{24-27} \mathrm{~A}$ growing body of research has found that early response is a robust predictor of later symptom response. ${ }^{28-33}$ Not only do these early responders demonstrate a greater reduction in symptoms later in the course of treatment than early nonresponders, but they also have better outcomes across a broad array of functional measures ${ }^{30,34}$ and reduced treatment costs. ${ }^{30}$ Understanding and maximizing early treatment response among patients with schizophrenia may help improve longer-term patient outcomes.

Examining the patient and treatment characteristics that predict early response may help physicians better maximize the rates of early response and the associated benefits. Little work to date has attempted to identify the characteristics of patients who are more likely to demonstrate an early response to antipsychotic treatment. Much of the work on early treatment response has been done using data from protocol-driven care drawn from randomized clinical trials rather than from observational or naturalistic studies and little data on early response have come from studies conducted in Asia. The objectives of this research were two-fold, ie, to identify predictors of early treatment response to olanzapine for patients with schizophrenia in the People's Republic of China and to examine the 6-month clinical and functional outcomes for early responders compared with early nonresponders.

\section{Materials and methods}

\section{Parent study}

Data for this post hoc analysis came from a large, multinational, noninterventional, observational study of outpatients with bipolar mania or schizophrenia who were initiating or switching to treatment with oral olanzapine. ${ }^{35}$ The parent study included 622 eligible patients who enrolled between June 2005 and December 2006 from 37 sites in the People's Republic of China, Romania, Mexico, and Taiwan. The current analysis was restricted to the subset of $330(53.1 \%)$ Chinese patients with a diagnosis of schizophrenia.

Measures were collected at baseline then once per month ( \pm 2 weeks) at regularly scheduled visits over the 6-month study period. All treatment decisions, including the decision to initiate olanzapine therapy, were at the discretion of the treating physician and the patient. Consistent with usual 
clinical care, concomitant medications were permitted. If a patient discontinued olanzapine treatment, measures were still collected provided the patient remained in the study. In some cases, the patient may have both discontinued and restarted olanzapine during the 6-month study period. In this naturalistic, observational study the patient could have been enrolled in weight control programs. The institutional review board at each study site approved the study. All patients or their legal guardians gave signed informed consent. The study sponsor did not provide medications and the patients were not paid for their participation in the study.

\section{Inclusion/exclusion criteria}

To maximize external validity, the parent observational study used broad inclusion and exclusion criteria. All patients were at least 18 years of age, treated in outpatient, ambulatory care, or community settings, and had recently switched antipsychotic treatment to or initiated antipsychotic treatment with oral olanzapine (either the standard tablets or the orally disintegrating tablet formulation). None of the patients were participating in a separate intervention study. In the current analytical sample, all patients were Chinese and had a diagnosis of schizophrenia based on DSM-IV-TR (Diagnostic and Statistical Manual of Mental Disorders, Fourth Edition, Text Revision) or ICD-10 (International Classification of Diseases Tenth Revision) criteria. Further details regarding the procedures of the parent study are available elsewhere. ${ }^{35}$

\section{Measures}

To minimize impact on usual clinical care, only brief measures were included in the study. The Clinical Global Impressions-Severity (CGI-S) scale is a seven-point clinician rating ranging from 1 (normal, not at all ill) to 7 (among the most extremely ill patients). ${ }^{36}$ Patient insight into illness was measured using a clinician rating ranging from 0 (none) to 4 (high). Work impairment was measured using a clinician rating ranging from 0 (no impairment) to 4 (unable to work due to mental illness). General life satisfaction was measured using a clinician rating ranging from 1 (very dissatisfied) to 5 (very satisfied). Finally, the number of social activities in the past month was measured using a clinician rating ranging from 0 to $5+$ activities. The measures and information used in this analysis could all be collected during routine clinical care.

\section{Definitions}

Patients were classified as adherent if the clinician rated them as at least $80 \%$ adherent with prescribed antipsychotic medication since the last assessment. Consistent with past research, response was defined as at least a 2-point decrease in the CGI-S for patients with a baseline score between 5 (markedly ill) and 7 (among the most extremely ill patients) or at least a one-point decrease for patients with a baseline score between 2 (borderline ill) and 4 (moderately ill). ${ }^{37,38}$ The primary independent variable, ie, early response, was defined as meeting the above definition of response at the first follow-up visit (month 1).

\section{Statistical analysis}

Differences between early responders and early nonresponders were examined at baseline. For numeric variables, these comparisons were completed with independent samples $t$-tests. For categorical variables, the baseline comparisons were completed using the Fisher's exact test or Monte Carlo simulation of the Fisher's exact test if the former was not feasible.

A stepwise logistic regression identified predictors of early response using baseline characteristics (Table 1) and medication adherence with olanzapine during the first month of treatment (ie, early adherence). Due to missing values on some predictor variables (for approximately $16 \%$ of patients), a sensitivity analysis was conducted to confirm the results. For the sensitivity analysis, a multiple imputation procedure was used to impute missing values and then stepwise logistic regression modeling was conducted on the imputed datasets. The nonimputed results were reported and represent the primary analysis.

Differences in outcomes between early responders and early nonresponders were modeled using mixed models for repeated measures that included the following baseline measures: the relevant baseline outcome variable, baseline dose of olanzapine, baseline body mass index, baseline CGI-S, baseline participation in a weight control program, age, sex, duration of illness, study visit, early responder status, and study visit by early responder status. When means are reported, they are accompanied by $( \pm)$ the standard deviations. The two-tailed significance level was set at $\alpha=0.05$. All analyses were completed using SAS software version 9.2 (SAS, Inc., Cary, NC, USA).

\section{Results Sample description}

Among the 330 Chinese patients in the parent study, ${ }^{35}$ six could not be classified on early response status and were excluded from the analysis. Five of these six patients had a baseline CGI-S of 1 and one patient did not have any followup CGI-S information. The final analytical sample consisted 
Table I Baseline characteristics

\begin{tabular}{|c|c|c|c|}
\hline Variable & $\begin{array}{l}\text { Early } \\
\text { nonresponders } \\
(n=194)\end{array}$ & $\begin{array}{l}\text { Early } \\
\text { responders } \\
(n=130)\end{array}$ & $P$-value \\
\hline Age, mean (SD), years & $30.2(11.1)$ & $27.8(9.1)$ & 0.036 \\
\hline Female, n (\%) & $100(5 \mathrm{I} .5)$ & 74 (56.9) & 0.365 \\
\hline Education, n (\%) & & & 0.727 \\
\hline$<$ High school & $48(24.9)$ & $27(20.8)$ & \\
\hline High school & $66(34.2)$ & $52(40.0)$ & \\
\hline University & 79 (40.9) & $51(39.2)$ & \\
\hline Marital status, n (\%) & & & 0.360 \\
\hline Married & $62(32.0)$ & $38(29.2)$ & \\
\hline Domestic partner & $105(54.1)$ & $66(50.8)$ & \\
\hline No relationship & $27(13.9)$ & $26(20.0)$ & \\
\hline Working for pay, n (\%) & $24(12.4)$ & $18(13.8)$ & 0.737 \\
\hline Any dependents, $\mathrm{n}(\%)$ & $89(46.4)$ & $65(50.0)$ & 0.570 \\
\hline $\begin{array}{l}\text { Duration of illness, } \\
\text { mean (SD), years }\end{array}$ & $5.3(8.7)$ & $2.4(4.7)$ & $<0.001$ \\
\hline Paranoid subtype, n (\%) & $115(59.6)$ & $84(65.1)$ & 0.350 \\
\hline $\begin{array}{l}\text { Antipsychotics or mood } \\
\text { stabilizers, }{ }^{a} \text { n (\%) }\end{array}$ & $128(66.0)$ & $95(73.1)$ & 0.181 \\
\hline $\begin{array}{l}\text { Other psychiatric } \\
\text { medications, }{ }^{\mathrm{a}} \mathrm{n}(\%)\end{array}$ & $74(38.1)$ & $38(29.2)$ & 0.121 \\
\hline $\begin{array}{l}\text { History of antipsychotic } \\
\text { treatment, }^{\mathrm{b}} \mathrm{n}(\%)\end{array}$ & $119(62.6)$ & $72(56.7)$ & 0.295 \\
\hline Ever smoked, n (\%) & $44(23.5)$ & $24(20.0)$ & 0.485 \\
\hline CGI-S, mean (SD) & $4.6(1.1)$ & $5.0(1.0)$ & 0.006 \\
\hline $\begin{array}{l}\text { Social activities, } \\
\text { mean (SD) }\end{array}$ & $\mathrm{I} .5(\mathrm{I} .7)$ & $2.0(1.9)$ & 0.037 \\
\hline Insight, mean (SD) & $\mathrm{I} .4(\mathrm{I} .3)$ & I.3 (I.I) & 0.444 \\
\hline $\begin{array}{l}\text { Impairment in work, } \\
\text { mean }(S D)\end{array}$ & $2.5(1.2)$ & $2.3(1.2)$ & 0.280 \\
\hline Life satisfaction, n (\%) & & & 0.089 \\
\hline Dissatisfied & $85(43.8)$ & $71(54.6)$ & \\
\hline Neither & $69(35.6)$ & $32(24.6)$ & \\
\hline Satisfied & $40(20.6)$ & $27(20.8)$ & \\
\hline BMI, mean (SD), $\mathrm{kg} / \mathrm{m}^{2}$ & $22.2(2.8)$ & $21.6(3.2)$ & 0.108 \\
\hline $\begin{array}{l}\text { Weight control program, } \\
\mathrm{n}(\%)\end{array}$ & $49(25.3)$ & $43(33.1)$ & 0.133 \\
\hline $\begin{array}{l}\text { Low physical activity, } \\
\mathrm{n}(\%)\end{array}$ & $21(10.8)$ & $7(5.4)$ & 0.107 \\
\hline $\begin{array}{l}\text { Prior AP weight gain, } \\
n(\%)\end{array}$ & $19(9.8)$ & $10(7.7)$ & 0.558 \\
\hline
\end{tabular}

Notes: ${ }^{a}$ At baseline or during the 6 months prior to baseline; bat any time in the patient's history.

Abbreviations: AP, antipsychotic; BMI, body mass index; CGI-S, Clinical Global Impressions-Severity; SD, standard deviation.

of 324 individuals, including 130 (40.1\%) early responders and 194 (59.9\%) early nonresponders. Almost all of the early responders $(n=128 ; 98.5 \%)$ and early nonresponders $(n=192$; 99.0\%) completed the 6-month study.

Table 1 gives the baseline comparison between the early responders and early nonresponders. Early responders were significantly younger, had a significantly shorter duration of illness, had significantly higher baseline CGI-S scores, and engaged in significantly more baseline social activities.

\section{Treatment description}

The average daily starting dose of olanzapine was $9.65 \pm 5.34 \mathrm{mg} / \mathrm{day}$ for the early responders and $9.33 \pm 5.52 \mathrm{mg} /$ day for the early nonresponders $(P=0.600)$. Across the 6-month study, the average prescribed daily dose of olanzapine increased to $11.52 \pm 4.58 \mathrm{mg} /$ day for the early responders and $12.66 \pm 5.44 \mathrm{mg} /$ day for the early nonresponders $(P=0.051)$. The majority of patients continued their olanzapine treatment throughout the study. At some point during the study, six (4.6\%) early responders and $17(8.8 \%)$ early nonresponders discontinued olanzapine $(P=0.188)$. At the one-month visit, antipsychotic polypharmacy was received by ten $(7.7 \%)$ of the early responders and $24(12.4 \%)$ of the early nonresponders $(P=0.200)$. Adherence $(\geq 80 \%)$ to prescribed antipsychotic treatment was significantly more common among early responders $(n=106 ; 84.1 \%)$ than the early nonresponders $(\mathrm{n}=127 ; 67.2 \%, P<0.001)$.

\section{Predictors of early response}

A stepwise logistic regression identified five variables that significantly predicted early response, ie, baseline CGI-S scores, duration of illness, baseline social activities, baseline enrollment in a weight control program, and early adherence to antipsychotic medication. The coefficients in the final model predicting early response included an intercept $(b=-2.66$, $P<0.001$ ), an increase for every additional point in baseline CGI-S ( $b=0.41, P=0.003$ ), an increase for every additional social activity (up to $5+$ ) at baseline ( $b=0.20, P=0.008$ ), a decrease for every year shorter on duration of illness $(b=-0.07$, $P=0.002$ ), an increase in the odds associated with participating in a weight control program at baseline versus nonparticipation ( $b=0.30, P=0.036$ ), and an increase in the odds for antipsychotic adherence ( $\geq 80 \%$ ) during the first month of treatment versus nonparticipation ( $b=0.55, P=0.001)$. Figure 1 presents the odds ratio (ORs) and 95\% confidence intervals (CIs) for each of the predictors. Early adherence was the first variable selected by the stepwise analysis. The $c$-statistic for the overall model was 0.71 , indicating that the model could correctly discriminate a randomly selected early responder from a randomly selected early nonresponder $71 \%$ of the time.

Only $271(83.6 \%)$ of 324 patients had complete data on all of the predictors in the stepwise logistic regression. To examine the potential effects of missing values, a sensitivity analysis was conducted using a multiple imputation procedure that generated ten imputed datasets. The ORs (95\% CIs) based on the imputed datasets were 1.59 (1.23-2.05) for the CGI-S, 1.31 (1.00-1.72) for the baseline weight control group, 1.58 (1.16-2.14) for early adherence, 1.20 (1.05-1.38) for social activities, and $0.93(0.89-0.98)$ for the duration 


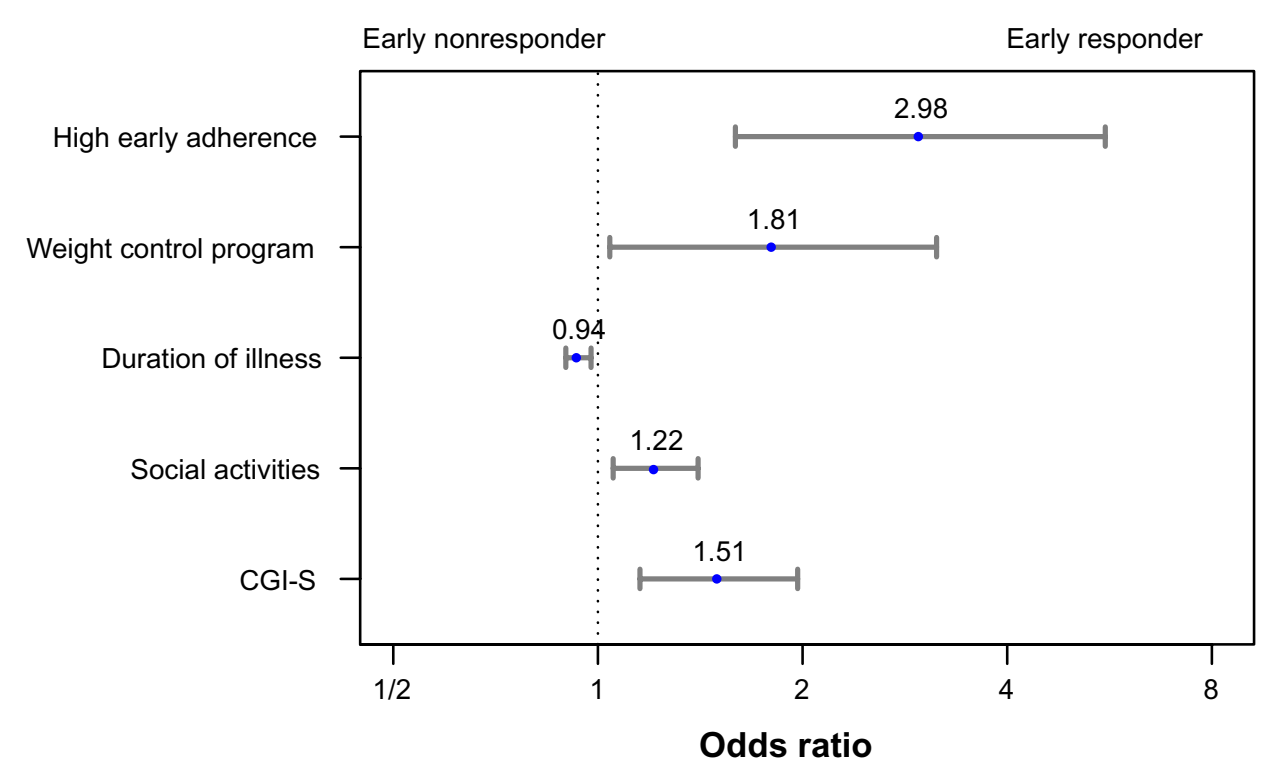

Figure I Odds ratios from logistic regression model.

Note: Duration of illness, number of social activities, and CGI-S are numeric variables so the odds ratios represent the change in odds for every unit increase in the variable.

Abbreviation: CGI-S, Clinical Global Impressions-Severity.

of illness. Although the direction and statistical significance remained the same for all of the predictors in the multiple imputation sensitivity analysis, the estimates and corresponding ORs were somewhat reduced for the adherence and baseline weight control group variables.

\section{Longer-term outcomes for early responders}

The early responders demonstrated significantly better improvements over the full 6-month study period across multiple outcome variables (Figures 2 and 3), ie, CGI-S
$(P<0.001)$, patient insight into illness $(P<0.001)$, number of social activities $(P=0.051)$, work impairment $(P<0.001)$, and general life satisfaction $(P=0.002)$. Most of the outcome variables showed significant improvements for the early responders at each visit, except for one visit for patient insight into illness, four visits for number of social activities, and one visit for general life satisfaction (Figures 2 and 3). There were no differences in body mass index or weight change between the early responders and early nonresponders at any visit. The average increase in body mass index at the 6-month visit was 1.60 points for the early responders and

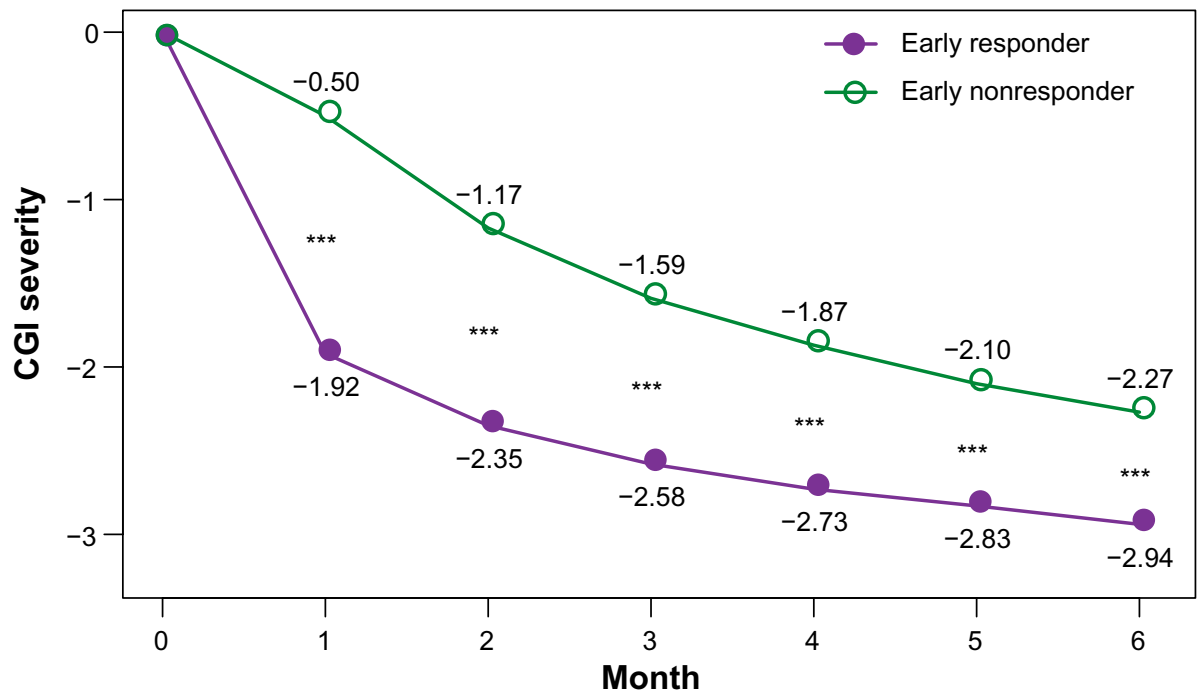

Figure 2 CGI-S change from baseline across the 6-month study for early responders versus early nonresponders.

Notes: The overall $P$-value for the early responder effect in the mixed models for repeated measures was $<0.001$. $* * * P<0.001$.

Abbreviation: CGI-S, Clinical Global Impressions-Severity. 

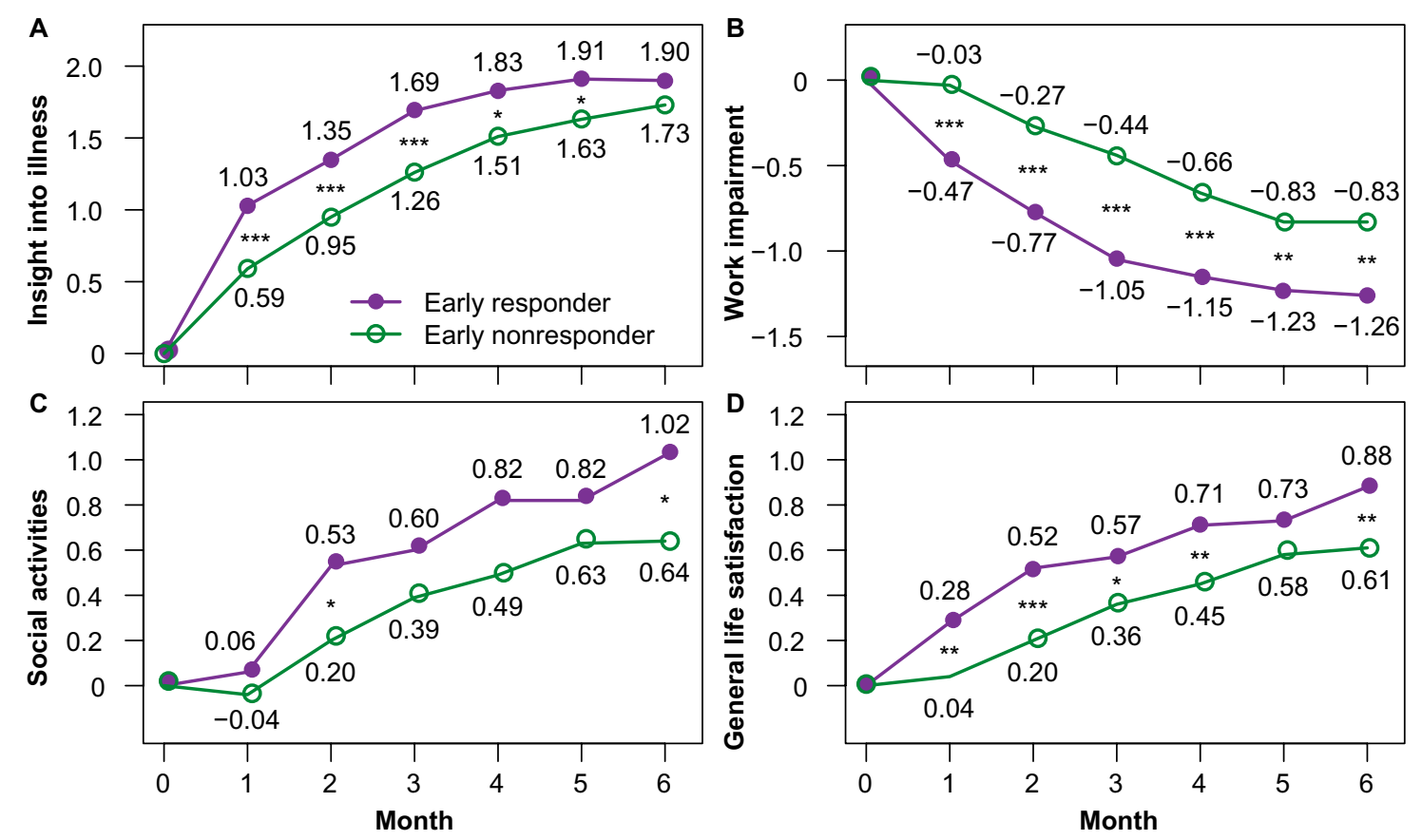

Figure 3 Change from baseline in functional outcomes across the 6-month study for early responders versus early nonresponders.

Notes: The overall $P$-values for the early responder effect in the mixed models for repeated measures were $<0.001,<0.001,0.05$ I, and 0.002 for patient insight into illness, work impairment, social activities, and life satisfaction changes, respectively. $* P<0.05$; $* * P<0.01$; $* * * P<0.001$.

1.57 points for the early nonresponders $(P=0.868)$. Similar to the change in body weight, there were no significant differences in overall weight gain at 6 months between early responders and early nonresponders $(4.38 \mathrm{~kg}$ versus $4.37 \mathrm{~kg}$, respectively; $P=0.993$ ).

Despite differences by early response status, most patients $(87.3 \%)$ responded to treatment by the end of the study. At the 6-month visit, with missing values imputed using the last observation carried forward method, 100\% (130/130) of the early responders and $78.9 \%$ (153/194) of the early nonresponders met the criteria for response. Although most patients in both groups responded, significantly more early responders than early nonresponders met the criteria for response at the end of the study $(P<0.001)$.

\section{Discussion}

Early responders to olanzapine could be identified with moderate accuracy (with a $c$-statistic of 0.71 ) based on predictors that are easily assessed in everyday inpatient or outpatient care: higher baseline CGI-S scores, shorter duration of illness, greater number of social activities, enrollment in a weight control program, and early adherence with prescribed antipsychotic medications. Early adherence with medication was the strongest (ie, it was selected as the first variable in the stepwise logistic regression) predictor of early response (OR 2.98). Across the 6-month study period, early responders had significantly better outcomes on multiple variables, including illness severity, insight into illness, work impairment, social activities, and general satisfaction with life. All (100\%) of the early responders and most (78.8\%) of the early nonresponders met the response criteria at the 6-month visit. Early treatment response appears to be an important early indicator of better longer-term outcomes across multiple domains.

Multiple previous studies have reported that early responders have greater longer-term improvements in symptoms and functioning. ${ }^{29,30,32,33,39,40}$ However, few studies have examined predictors of early treatment response. A positive early experience with medication may help bolster a therapeutic alliance and could potentially lead to better long-term outcomes. ${ }^{7}$ Early treatment response appears to be an important marker for better long-term outcomes that can be predicted based on baseline and early treatment characteristics.

Most of the predictors of early treatment response in the current study have been previously identified as predictors of overall treatment response. Duration of illness, ${ }^{37,41}$ as well as the related concept of duration of untreated psychosis, ${ }^{42}$ appear to be important predictors of poor response. Longer duration of untreated psychosis has been associated with greater reduction in temporal gray matter, ${ }^{43,44}$ raising the possibility that psychosis may be toxic to the brain. 
Treatment adherence is a well known predictor of outcomes and lack of adherence is one of the strongest predictors of relapse. ${ }^{15,16}$ Prior research in the People's Republic of China has also highlighted the importance of maintenance treatment and the relationship between the risk of relapse and poor treatment adherence. ${ }^{45}$ Higher baseline symptoms, particularly positive symptoms, have been previously associated with greater response rates. ${ }^{40}$ This may be an artifact of regression to the mean, which occurs when, by chance, a patient's symptoms were particularly severe on the day of the baseline measurement, and thus, the patient's symptoms are more likely to be lower in the future. Nonetheless, patients who experience more pronounced acute positive symptoms appear to be more responsive to treatment. A higher level of social activity may reflect better premorbid functioning, which has been linked to better treatment response, ${ }^{42}$ but the predictive value of social activity for predicting early response warrants further investigation. Two of the predictors, early adherence and enrollment in a weight control program, stand out because they may be modifiable.

The identification of early nonresponse may alert clinicians to potential adherence issues. Treatment adherence in the People's Republic of China appears to be improved by psychosocial interventions, including cognitive behavioral approaches and family interventions. ${ }^{46}$ Recommendations for improving adherence in clinical practice include developing tailored treatment plans to meet an individual's needs, enhancing therapeutic alliance, using the most suitable route of delivery of antipsychotic medication that is related to better adherence profiles, ensuring optimal effectiveness and continuity of care, and involving key individuals and family members in care and psychoeducation of the patient. ${ }^{47}$

The first month of treatment is an important period for identifying not only patients who could benefit from the longer-term effectiveness of olanzapine, but also patients who have a potential for substantial weight gain. A unique predictor of early response identified in this study was participation in a weight control program. Weight control programs have been found to be effective in reducing the amount of weight gain for patients treated with antipsychotics. ${ }^{48-50} \mathrm{~A}$ recent study found that participation in a weight control program was associated with greater improvements in patient insight and better clinical and functional rehabilitation. ${ }^{51,52}$ Patients who experience significant weight gain at the beginning of therapy may be at risk of interrupting their antipsychotic treatment, even if it is effective. These patients should be referred to weight control programs, which could allow them to continue antipsychotic treatment and experience improved longer-term clinical and functional rehabilitation.

For patients with schizophrenia, the most effective treatments may also be the most cost-effective treatments. The personal, economic, and societal burden of schizophrenia is high, and when treated effectively, patients tend to persist longer with antipsychotic treatment, have fewer costly relapses, and have improved functioning. ${ }^{53}$ A recent analysis in Tianjin, People's Republic of China, reported that patients with inpatient costs had almost ten times the cost of those without inpatient treatment. ${ }^{54}$ Inpatient psychiatric hospitalizations were found to be the main driver of direct treatment costs in schizophrenia, and treatment strategies aimed at reducing the hospitalization rate for patients with schizophrenia may yield substantial cost savings in the People's Republic of China. ${ }^{55}$ The recently introduced Mental Health Rights Law and the ongoing Mental Health Care Reform in the People's Republic of China will likely extend current outpatient services and increase the demand for effective outpatient treatment strategies that improve patient functionality and reduce the need for more expensive inpatient care. ${ }^{56,57}$

\section{Switching early nonresponders}

Prior studies finding that early nonresponse (usually at 2 weeks) was a strong predictor of later nonresponse raised the possibility of switching medication earlier rather than following the traditional recommendation in case of a delayed response. ${ }^{58}$ The results of this study were not supportive of this strategy, given that approximately $80 \%$ of the early nonresponders met the response criteria at the 6-month visit. Although response at weeks 1-2 has been accurate in predicting response at weeks $8-12,{ }^{30,32,33}$ the 12-month response appears to be better predicted by the 6-week response than the 1-2-week response. ${ }^{39}$ A randomized controlled trial found that switching early risperidone nonresponders to olanzapine resulted in modest improvements relative to remaining on risperidone; ${ }^{33}$ however, the early responders had much better longer-term responses than early nonresponders who were switched. ${ }^{33,59}$ The early nonresponders appear to represent a group of patients who are less responsive to treatment.

In CATIE (Clinical Antipsychotic Trials of Intervention Effectiveness), individuals who discontinued their antipsychotic in the first phase of the study could have been randomly assigned to the same antipsychotic again in the next phase of the study. The olanzapine-treated patients who were randomly assigned to continue olanzapine had a significantly longer 
time to discontinuation than the olanzapine patients who were randomly assigned to switch to risperidone or quetiapine. ${ }^{60}$ Prior to switching early olanzapine nonresponders to another medication, optimizing the dose may be prudent given that increasing the dose of olanzapine has been shown to improve efficacy. ${ }^{61}$

\section{Limitations}

This was a post hoc analysis from an observational study of treatment with olanzapine in the People's Republic of China. Use of concomitant medications, including antipsychotics in usual clinical care, may have improved the longer-term response rate relative to continuing treatment with olanzapine monotherapy. Therefore, early nonresponse may have been a better predictor of later nonresponse if treatment had been restricted to antipsychotic monotherapy. This study relied on simple measures to minimize interference with usual clinical care. Use of more intensive and better validated measures, such as the Positive and Negative Syndrome Scale, may have given more precise results. The majority of assessments used in this study were clinician-completed, and the use of patient self-report measures may show different results. As with all observational research, groups were not formed using randomization; therefore, the comparisons could possibly be biased due to unmeasured confounders. Response to antipsychotics does not imply remission or recovery in schizophrenia.

\section{Conclusion}

Consistent with previous research from outside of the People's Republic of China, early responders had significantly better longer-term clinical and functional outcomes. The ultimate long-term treatment goal in schizophrenia is to reintegrate patients into society. Reintegration will likely require maintaining treatment with an effective antipsychotic while maximizing the benefit/risk ratio, avoiding relapse and hospitalization, and improving functional outcomes and quality of life. Early interventions that may lead to better longer-term outcomes for olanzapine-treated patients include enrolling patients in weight control programs, encouraging early treatment adherence, and promoting participation in social activities.

\section{Author contributions}

WY, WM, ZK, LL, HBX, MS, and TT were involved in the study design, data collection, data analysis, or preparation and review of the manuscript. All authors approved the final version of the manuscript.

\section{Disclosure}

Funding for this study was provided by Eli Lilly and Company. WY, WM, ZK, LL, HX, and TT are all employees of Eli Lilly and Company or one of its wholly owned subsidiaries. MS is the owner of Agile Outcomes Research Inc., a company that was hired by the sponsor to assist with this research.

\section{References}

1. Falkai P, Wobrock T, Lieberman J, Glenthoj B, Gattaz WF, Möller H-J. World Federation of Societies of Biological Psychiatry (WFSBP) guidelines for biological treatment of schizophrenia, part 1: acute treatment of schizophrenia. World J Biol Psychiatry. 2005;6(3):132-191.

2. Mathers C, Boerma T, Fat DM. The Global Burden of Disease: 2004 Update. Geneva, Switzerland: World Health Organization Press; 2008.

3. BuckleyPF, Wirshing DA, Bhushan P, Pierre JM, ResnickSA, Wirshing WC. Lack of insight in schizophrenia: impact on treatment adherence. CNS Drugs. 2007;21(2):129-141.

4. Karagianis J, Novick D, Pecenak J, et al. Worldwide-Schizophrenia Outpatient Health Outcomes (W-SOHO): baseline characteristics of pan-regional observational data from more than 17,000 patients. Int $J$ Clin Pract. 2009;63(11):1578-1588.

5. Marwaha S, Johnson S. Schizophrenia and employment. Soc Psychiatry Psychiatr Epidemiol. 2004;39(5):337-349.

6. Falkai P, Wobrock T, Lieberman J, Glenthoj B, Gattaz WF, Möller H-J. World Federation of Societies of Biological Psychiatry (WFSBP) guidelines for biological treatment of schizophrenia, part 2: long-term treatment of schizophrenia. World J Biol Psychiatry. 2006;7(1):5-40.

7. Lehman AF, Lieberman JA, Dixon LB, et al. Practice guideline for the treatment of patients with schizophrenia, second edition. Am J Psychiatry. 2004;161(Suppl 2):1-56.

8. Leucht S, Komossa K, Rummel-Kluge C, et al. A meta-analysis of head-to-head comparisons of second-generation antipsychotics in the treatment of schizophrenia. Am J Psychiatry. 2009;166(2):152-163.

9. Lieberman JA, Stroup TS, McEvoy JP, et al. Effectiveness of antipsychotic drugs in patients with chronic schizophrenia. $N$ Engl $J$ Med. 2005;353(12):1209-1223.

10. Rummel-Kluge C, Komossa K, Schwarz S, et al. Head-to-head comparisons of metabolic side effects of second generation antipsychotics in the treatment of schizophrenia: a systematic review and meta-analysis. Schizophr Res. 2010;123(2-3):225-233.

11. Leucht S, Kissling W, Davis JM. Second-generation antipsychotics for schizophrenia: can we resolve the conflict? Psychol Med. 2009;39(10):1591-1602.

12. Kiviniemi M, Suvisaari J, Koivumaa-Honkanen H, Häkkinen U, Isohanni M, Hakko H. Antipsychotics and mortality in first-onset schizophrenia: prospective Finnish register study with 5-year follow-up. Schizophr Res. 2013;150(1):274-280.

13. Yao X, Wu J, Liu L, Ye W, Xue H, Montgomery W. Medication use patterns and adherence after initiating antipsychotics treatment for patients with schizophrenia in Tianjin, China. Value Health. 2013;16(7):A554.

14. Olivares JM, Thirunavukarasu M, Kulkarni J, Zhang HY, Zhang M, Zhang F. Psychiatrists' awareness of partial and nonadherence to antipsychotic medication in schizophrenia: results from an Asia-Pacific survey. Neuropsychiatr Dis Treat. 2013;9:1163-1170.

15. Ayuso-Gutiérrez JL, del Río Vega JM. Factors influencing relapse in the long-term course of schizophrenia. Schizophr Res. 1997;28(2-3): 199-206.

16. Robinson D, Woerner MG, Alvir JM, et al. Predictors of relapse following response from a first episode of schizophrenia or schizoaffective disorder. Arch Gen Psychiatry. 1999;56(3):241-247.

17. Law MR, Soumerai SB, Ross-Degnan D, Adams AS. A longitudinal study of medication nonadherence and hospitalization risk in schizophrenia. J Clin Psychiatry. 2008;69(1):47-53. 
18. Weiden PJ, Kozma C, Grogg A, Locklear J. Partial compliance and risk of rehospitalization among California Medicaid patients with schizophrenia. Psychiatr Serv. 2004;55(8):886-891.

19. Lacro J, Dunn L, Dolder C, Leckband S, Jeste D. Prevalence of and risk factors for medication nonadherence in patients with schizophrenia: a comprehensive review of recent literature. J Clin Psychiatry. 2002;63(10):892-909.

20. Ascher-Svanum H, Zhu B, Faries DE, Lacro JP, Dolder CR, Peng X. Adherence and persistence to typical and atypical antipsychotics in the naturalistic treatment of patients with schizophrenia. Patient Prefer Adherence. 2008;2:67-77.

21. Tunis SL, Faries DE, Stensland MD, Hay DP, Kinon BJ. An examination of factors affecting persistence with initial antipsychotic treatment in patients with schizophrenia. Curr Med Res Opin. 2007;23(1):97-104

22. Lang K, Meyers J, Korn J, et al. Medication adherence and hospitalization among patients with schizophrenia treated with antipsychotics. Psychiatr Serv. 2010;61(12):1239-1247.

23. Ascher-Svanum H, Nyhuis AW, Stauffer V, et al. Reasons for discontinuation and continuation of antipsychotics in the treatment of schizophrenia from patient and clinician perspectives. Curr Med Res Opin. 2010;26(10):2403-2410.

24. Case M, Stauffer VL, Ascher-Svanum H, et al. The heterogeneity of antipsychotic response in the treatment of schizophrenia. Psychol Med. 2011;41(6):1291-1300.

25. Lipkovich IA, Deberdt W, Csernansky JG, et al. Defining "good" and "poor" outcomes in patients with schizophrenia or schizoaffective disorder: a multidimensional data-driven approach. Psychiatry Res. 2009;170(2-3):161-167.

26. Nordon C, Rouillon F, Azorin JM, Barry C, Urbach M, Falissard B. Trajectories of antipsychotic response in drug-naive schizophrenia patients: results from the 6-month ESPASS follow-up study. Acta Psychiatr Scand. 2014;129(2):116-125.

27. Schennach R, Meyer S, Seemüller F, et al. Response trajectories in "real-world" naturalistically treated schizophrenia patients. Schizophr Res. 2012;139(1-3):218-224.

28. Agid O, Kapur S, Arenovich T, Zipursky RB. Delayed-onset hypothesis of antipsychotic action: a hypothesis tested and rejected. Arch Gen Psychiatry. 2003;60(12):1228-1235.

29. Agid O, Siu CO, Pappadopulos E, Vanderburg D, Remington G. Early prediction of clinical and functional outcome in schizophrenia. Eur Neuropsychopharmacol. 2013;23(8):842-851.

30. Ascher-Svanum H, Nyhuis AW, Faries DE, Kinon BJ, Baker RW, Shekhar A. Clinical, functional, and economic ramifications of early nonresponse to antipsychotics in the naturalistic treatment of schizophrenia. Schizophr Bull. 2008;34(6):1163-1171.

31. Ascher-Svanum H, Zhao F, Detke H, et al. Early response predicts subsequent response to olanzapine long-acting injection in a randomized, double-blind clinical trial of treatment for schizophrenia. $B M C$ Psychiatry. 2011;11(1):152.

32. Kinon BJ, Chen L, Ascher-Svanum H, et al. Predicting response to atypical antipsychotics based on early response in the treatment of schizophrenia. Schizophr Res. 2008;102(1-3):230-240.

33. Kinon BJ, Chen L, Ascher-Svanum H, et al. Early response to antipsychotic drug therapy as a clinical marker of subsequent response in the treatment of schizophrenia. Neuropsychopharmacology. 2010;35(2):581-590.

34. Kinon BJ, Chen L, Ascher-Svanum H, et al. Challenging the assumption that improvement in functional outcomes is delayed relative to improvement in symptoms in the treatment of schizophrenia. Schizophr Res. 2010;118(1):176-182.

35. Treuer T, Hoffmann VP, Chen AK-P, et al. Factors associated with weight gain during olanzapine treatment in patients with schizophrenia or bipolar disorder: results from a six-month prospective, multinational, observational study. World J Biol Psychiatry. 2009;10(4 Pt 3): 729-740.

36. Guy W. ECDEU Assessment Manual for Psychopharmacology. Rockville, MD, USA: US Department of Health, Education, and Welfare; 1976.
37. Brousse G, Meary A, Blanc O, Lançon C, Llorca PM, Leboyer M. Clinical predictors of response to olanzapine or risperidone during acute episode of schizophrenia. Psychiatry Res. 2010;179(1):12-18.

38. Haro JM, Edgell ET, Novick D, et al. Effectiveness of antipsychotic treatment for schizophrenia: 6-month results of the Pan-European Schizophrenia Outpatient Health Outcomes (SOHO) study. Acta Psychiatr Scand. 2005;111(3):220-231.

39. Schennach R, Riesbeck M, Mayr A, et al. Should early improvement be re-defined to better predict the maintenance of response in firstepisode schizophrenia patients? Acta Psychiatr Scand. 2013;127(6): $474-481$.

40. Schennach-Wolff R, Jäger M, Mayr A, et al. Predictors of response and remission in the acute treatment of first-episode schizophrenia patients - is it all about early response? Eur Neuropsychopharmacol. 2011;21(5):370-378.

41. Schennach-Wolff R, Meyer S, Seemüller F, et al. Influencing factors and predictors of early improvement in the acute treatment of schizophrenia and schizophrenia spectrum disorder. $J$ Psychiatr Res. 2011;45(12):1639-1647.

42. Perkins D, Lieberman J, Gu H, et al. Predictors of antipsychotic treatment response in patients with first-episode schizophrenia, schizoaffective and schizophreniform disorders. Br J Psychiatry. 2004;185:18-24.

43. Emsley R, Chiliza B, Schoeman R. Predictors of long-term outcome in schizophrenia. Curr Opin Psychiatry. 2008;21(2):173-177.

44. Lappin JM, Morgan K, Morgan C, et al. Gray matter abnormalities associated with duration of untreated psychosis. Schizophr Res. 2006;83(2-3):145-153.

45. Xiang Y-T, Wang C-Y, Weng Y-Z, et al. Predictors of relapse in Chinese schizophrenia patients: a prospective, multi-center study. Soc Psychiatry Psychiatr Epidemiol. 2011;46(12):1325-1330.

46. Barkhof E, Meijer CJ, de Sonneville LMJ, Linszen DH, de Haan L. Interventions to improve adherence to antipsychotic medication in patients with schizophrenia - a review of the past decade. Eur Psychiatry. 2012;27(1):9-18.

47. Cañas F, Alptekin K, Azorin JM, et al. Improving treatment adherence in your patients with schizophrenia: the STAY initiative. Clin Drug Investig. 2013;33(2):97-107.

48. Bonfioli E, Berti L, Goss C, Muraro F, Burti L. Health promotion lifestyle interventions for weight management in psychosis: a systematic review and meta-analysis of randomised controlled trials. BMC Psychiatry. 2012;12(1):78.

49. Faulkner G, Cohn T, Remington G. Interventions to reduce weight gain in schizophrenia. Schizophr Bull. 2007;33(3):654-656.

50. Gabriele JM, Dubbert PM, Reeves RR. Efficacy of behavioural interventions in managing atypical antipsychotic weight gain. Obes Rev. 2009;10(4):442-455.

51. Montgomery W, Treuer T, Ye W, et al. Does participation in a weight control program also improve clinical and functional outcomes for Chinese patients with schizophrenia treated with olanzapine? Value Health. 2012;15(7):A669.

52. Montgomery W, Treuer T, Ye W, et al. Does participation in a weight control program also improve clinical and functional outcomes for Chinese patients with schizophrenia treated with olanzapine? Neuropsych Dis Treat. In press 2014

53. Montgomery W, Liu, Ascher-Svanum H, Xue, Treuer T, Stensland M. The personal, societal, and economic burden of schizophrenia in the Peoples Republic of China: implications for antipsychotic therapy. Clin Outcomes Res. 2013;5:407-418.

54. Liu L, Ye W, Xiaoning H, Wu J, Montgomery W, Xue HB. Differential resource use and costs among inpatients and outpatients with schizophrenia in Tianjin, China. Proceedings of the 4th World Congress of Asian Psychiatry, Bangkok, Thailand, August 20-23, 2013.

55. Xiaoning $\mathrm{H}, \mathrm{Wu}$ J, Liu L, Montgomery W, Ye W, Xue HB. Health care resource utilization and direct medical costs among patients with schizophrenia in Tianjin, China. Proceedings of the 4th World Congress of Asian Psychiatry, Bangkok, Thailand, August 20-23, 2013. 
56. Chen HH, Phillips MR, Cheng H, et al. Mental health law of the People's Republic of China (English translation with annotations). Shanghai Arch Psychiatry. 2012;24(6):305-321.

57. Hvistendahl M. World's biggest health care system goes under the knife. Science. 2013;339(6119):505-507.

58. Gardner KN, Bostwick JR. Antipsychotic treatment response in schizophrenia. Am J Health Syst Pharm. 2012;69(21):1872-1879.

59. Hatta K, Otachi T, Sudo Y, et al. Difference in early prediction of antipsychotic non-response between risperidone and olanzapine in the treatment of acute-phase schizophrenia. Schizophr Res. 2011;128(1-3): $127-135$.
60. Essock SM, Covell NH, Davis SM, Stroup TS, Rosenheck RA, Lieberman JA. Effectiveness of switching antipsychotic medications. Am J Psychiatry. 2006;163(12):2090-2095.

61. Suarez D, Haro JM, Novick D, Perrin E, Ochoa S, Naber D. Reasons and outcomes of olanzapine dose adjustments in the outpatient treatment of schizophrenia. Pharmacopsychiatry. 2009;42(4):135-140.

\section{Publish your work in this journal}

Neuropsychiatric Disease and Treatment is an international, peerreviewed journal of clinical therapeutics and pharmacology focusing on concise rapid reporting of clinical or pre-clinical studies on a range of neuropsychiatric and neurological disorders. This journal is indexed on PubMed Central, the 'PsycINFO' database and CAS.
The manuscript management system is completely online and includes a very quick and fair peer-review system, which is all easy to use. Visit http://www.dovepress.com/testimonials.php to read real quotes from published authors.

Submit your manuscript here: http://www.dovepress.com/neuropsychiatric-disease-and-treatment-journal 